\title{
IMPORTÂNCIA DO BRINQUEDO NO DESENVOLVIMENTO DA CRIANÇA
}

Nahyda de Almeida Velloso*

Em publicação anterior sôbre o meamo as sunto * referimo-nos a certas caracteristicas da criança até 10 anos e suas preferéncias quanto aos brinquedos, tendo-nos prendido, especificamente, ì orientaçäo sobre os brinquedos mais adequados ao seu desenvolvimento nas idades de zero a 2 (dois) anos.

Procuraremos, rieste artigo, seguir aquela mesma sequéncia em relação às idades de 3 a 10 anos.

$$
\text { Criangas de } 3 \text { a } 10 \text { anos }
$$

Aos 3 an 0 - A criança nesta idade já se mo vimenta livre graciosamente, num ato puramente reflexo, bus cando novos ambientes quando passado o interésse naquilo que a rodeia.

A palavra, antes um simples sinal represen tativo de coisas concretas, val adquirindo um valor autónomo e abstrato, traduzindo o pensamento. $\dot{\xi}$ a organizaçāo de seu mundo interior capaz de combinar recordaçöes e de criar situ açōes fantásticas que ela vive com entusianmo e realismo. (Quâ quer pedaço de madeira pode ser transformado em cavalo, no qual monta e faz correr como se fôsse verdadeirol.

- Professóra de Enfermagem Pediátrica.

* Revista Paulista de Hospitais, fev. de 1960, p.34-37. 
As exigéncias sociais crescem; o respeito à propriedade alhela, a partilha de brinquedos, de atençöes e ou tros requintes sociais the sīo exiffidos. Há fixaçöo dos limi tes de sua propriedade impostos pelo adulto; em alguns objetos ela pode pegar, outros lhes säo proibidos. Subordinada a essa limitaçāo de propriedade a criança defende com muito mais ar dor o que é seu, usando freqilentemente a palavra "meu".

Embora haja muita individualidade no brin quedo, já começa o intercámbio de idéias entre as crianças. É - inicio do brinquedo em grupo ou cooperativo, mas de modo fu gaz; gostam de estar no convivio das outras, usarem 08 mes mos brinquedos, mas brincam isoladamente, cada qual com 0 seu.

Podemos dizer que do brinquedo puramente funcional da primeira Infáncia, a criança, impulgionada pela sua imaginação, começa o brinquedo fictício: imita tudo e to dos. Neste período mantém atitude mais contemplativa que ati va; é mais espectador que protagonista.

Faz tudo que fazia aos dois anos, mas com maior facilldade e coordenaçāo. Domina, ainda, a fase moto ra; corre, pode mudar a direção da marcha, pula objetos que encontra, sobe e desce escadas apoiando-se no corrimão. En fim pöe em açāo tôda sua atividade motora. O velocípede, a bọ la ou qualquer brinquedo que satisfaça aquela atividade devero ser-lhes propor cionados.

A preferência no uso da mão direita ou eg querda se acentua; começa a predominància unilateral.

Desperta para a expressão gráfica, rablsca com giz, lápis e mesmo com objetos ponteagudos a superfície lisa. Os móveis e paredes riscados trazem certo nervosismo aos pais que näo aceitam isso como um desenvolvimento nor mal, mas como destruiçāo.

Os mesmos brinquedos usados no 29 ano de vida tomar caracteristicas diferentes; a boneca que antes a 
menina só carregava pelos cabelos ou pelos braços, representa a filha na qual ela pode descarregar seus impulsos agressivos e afetivos. Nesta Idade a criança gosta muito tambem dos ani mais feltos de retalhos de pano ou feltro, cujo énchimento pode ser de algodāo, palba ou meamo pano cortado em pequenos pe daços. Tudo the serve para viver oua fantasia e impor seu po der de vontade, dando ao brinquedo ordens para falar, dormir, comer, Imitando a vida da família em relaçāo a ela e aos outros.

Recortes, colagen, pintura, modelagem,ins trumentos com ruídos, mústca, estórias, maferial de constrú ção, tudo agrada e diverte a crlança auxiliando o desenvolvimen to de atitudes construtivas tais como responsabilidade, iniciati va, adaptaçēo aos grupos e outras que, gradativamente, vão to mando parte na formação de sua personalidaise.

Os passeios constituem para ela uma forma de brinquedo necessário à sua infindável ânsia de ambulação e de expangäo de ambiente.

Dos 4 a 6 anos - Até os 3 anos a criança sú bia uma escada colocando um pé e depois outro no mesmo de grau; já agora o faz alternando um pé em cada degrau. Tôdas as suas atividades motoras da etapa anterior se tornam perfei tas an redor dos 5 ou 6 anos.

Adquire outras habllidades como andar de bi clcleta, movimentar-se mantando-se em equilibrio em um só pé, subir em árvores ou móveis e tantas outras colsas, que se ria interminável citar.

Pode-se dizer que é uma fase de equilíbrio, tanto na superfície líquida, como em superfícies estreitas (mu ros, cêrcas, beiradas de canteiros, etc.) em que se movimen ta com facilidade.

AOs 4 anos já ampliou seu contato social den tro e fora do ambiente famillar, urinca em casa de vizinhos e no Jardim da Infáncia. 
No decurso do 59 e 69 ano já brinca em grú pos, mes näo segue a regra do jôgo, entra e sal dêle movida por brigas e discussöes, porque cada qual quer faxer o que lhe parece certo; nāo sabe acettar derrota e procura empregar a fraude para evitá-la, acreditando que os outros fazem o mesmo.

Com o desenvalvimento dos músculos finos dos dedos já é capar de pintar uma figura respeitando as bor das do desenho, o que não conseguia aos 4 anos. As peças pe quenas para construgäo são usadas com grande babilldade; cong trói pontes, muros, portōes, casinhas, tudo que já teve oportú nidade de ver na realldade on em gravurab.

A linguagem, em progresso, enriquece-se com o aumento do número de palavras. As idéiss säo parado xais, ora raciocinando com deduçōes lógicas, sugerindo um sü per desenvolvimento, ora com incoerenciss.

Até 084 anos as estórias fantásticas a atra lam mais; dos 5 em diante säo estórlas reais as que mais deṣ pertam seu interésse, fatos notórios contemporáneos, incluindo homens atuais que väo se projetar na história da humanidade.

O brinquedo dramático e imitativo reprodu zindo a vida familiar substitui a construçäo, cujo interêsse dô minante demonstrava aos 4 anos. Gradativamente as crianças vāo se unindo, formando grupos e ampliando as amizades, desen volvendo-se socialmente, adquirindo habilidade de conviver com os outros e adotando a cooperagão como necessidade da ligaçāo membro-grupo.

Continua o desenvolvimento artístico $\operatorname{com} a$ modelagem, pintura, música, teatrinho de fantoches, etc.

Os sexos começam a se diferenciar; as meni nas escolhem brinquedos e jogos de natureza mais sedentária, copiando ou se identificando com a māe; panelas, fogāo, louças, bonecas sāo usadas, reproduzindo a vida do lar. Os meninos preferem 08 brinquedoB de maior atividade como escorregado res, patins, bicicletas, material de jardinagem e muitos outros. 
Isto nāo quer dizer qque as meninas nāo se utilizem dêstes brin quedos, embora 08 meninos, raramente, usem os delas.

Durante 069 ano a criança demonstra certa instabilidade emocional; é delicada e ríbpida, hostil e meiga, perdé com facilidade o humor, recuperando-o logo após para se mostrar boa e generosa.

Dos 6 a 10 anos - Do 69 ano em diante a crian ça, já com maturidade das funçōes psico-matoras, movimentan do-se com inteira cooperação dos músculos extensores e flexo res, com suas percepçōes visuais, táteis e auditivas altamente desenvolvidas e certa independência da mãe, está pronta para fazer sua integração na vida escolar.

Tôda atividade motora do período anterior é festa com mais rapidez e graça; 08 meninos demonstram habi lidade no jôgo de futebol e as meninas em pular uma corda em mapimento. AOs 8 anos elas saem e entram na corda em movi mento e pulam sem pisar na mesma, revelando maior coorde naçāo de movimentos.

Geralmeate nesta idade $a$ mímica e gesticu laçāo adquirem uma característica exagerada, principalmente na dramatização das situaçöes. AOs $\theta$ e 10 anos as crianças concentram, por mais tempo, a funçāo muscular numa ativi dade única até tornarem-se cansadas. Têm mais coordeaaçāo manual-visual mostrando em seus desenhos mais perspectiva.

O jôgo cooperatívo já iníciadoe desenvolvi do adquire, agora, todo o seu valor, seguindo obedientemen te regras estabelecidas. O conceito de propriedade bastante evo luldo faz da criança um respeitador'dos pertences alheios e um preservador do que é seu. Gosta de colecionar figurinhas por que éste tipo de coleção dá maior possibilidade de trocas quan do há repeticão, oferecendo ótimas oportunidades para novos contatos e amirades, ampliando seu campo social. Fmbora ha ja neste período certo desprézo entre os sexos, ambos apreciam as coleçōes. 
Só dêste período em diante os brinquedos mecânicos têm seu valor, porque estimulam o interésse pela mecânica e física.

A linguagem rica facilita à criança contar eg tórias, fazer apreciaçōes e mesmo discutir problemas políti cos e sociais, emitindo conceitos proprios.

Como proporcionar recreaçäo de modo económico

No artigo já citado orientamos os pais sôbre como recrear de maneira mais económica; neste, tentaremos dar algumas sugestōes para que a criança de 3 anos em diante tome parte ativa na confeç̧ão de seus próprios brinquedos auxi liada, ocasionalmente, pelos pais. Bríncando ela os constrói, e podemos afirmar que é o início da passagem do brinquedo ao trabalho.

Aos 3 anos a criança tem muito interésse no brinquedo com água e areia; formando seu barro, ela inicia a construçāo. Também a pintura a atrai oferecendo ocasiāo pa ra demonstrar preferéncias artísticas. Para a execuçāo da pin tura, basta fazer um pouco de mingau de maizena, dividir em di versas latinhas para que a criança misture em cada uma a côr (anilina ou pó, de pintor) que desejar, pintando em qualquer pa pel, com a mão ou com pince.. Também o giz de côr umedect do com gôma-árábica é apreciado.

Os blocos ou pedaços de madeira cortados em diferentes formas geométricas estimularão a Imaginação da criança nas mais variadas construçōes. As bonecas de pano, de meia, de palha ou de corda servem para imitar a vida do lar.

A medida que a criança vai adquirindo ou tras habiludades, estas deverāo ser aproveltadas, sem forçá-Ia entretanto a ir além daquilo que tstá capacitada. 
AOs 4 anos ela pode fazer seus colares ou pulseiras de brinquedo, tingindo e enfiando em cordāo pedaços de macarräo grosso; é uma tarefa agradável e multo contribui para o desenvolvimento dos músculos sinos dos dedos. Tam bém as conchinhas colhidas na s praias sāo usadas como enfeite de diversos objetos.

Os quebra-cabeças podem ser feltos pela própria criança recortando figuras de revistas, colando em pa peläo e, depois, dividindo em pedaçōs para que, unindo-os nova mente, possa recompor a figura. claro que as de majs idade farāo o quebra-cabeça com maior número de peças.

Acima de 4 anos a criança já tem certa habi lidade em conviver e cooperar com as outras, por isso são de valor os brinquedos para o seu desenvolvi_nento social.

Os jogos de dama podem ser feitos por elas em madeira ou qualquer papel colado em papelāo, quadriculan do-os e pintando-os em duas côres, fazendo, também, as pedri nhas de papelāo, madeira ou rolha, recortadas em forma esfé rica e pintadas.

Dramatizando e imitando, as crianças pode rāo fazer o equipamento de pescaria, usando varas finas com cordāo dependurado e na ponta um arame em forma de anzol. Fabricarāo seus peixes, com papelāo recortado e pintado, colo cando na cabeça uma argolinha de arame. Um cobertor poderá ser usado para formar as ondas, nas quais seräo colocados os peixes com a cabeça para fora. Inicia-se, entāo, a pescaria e a competição.

As meminas entregam-se à costurar para suas bruxas ou à confecção das mesmas, procurando represen tar a atividade do próprio lar.

Os fantoches feltos de pano ou de massa de papel e farinha de trigo, com figuras representativas de estó rias, sāo de fácil manejo e de grande diversāo. Também as 
figuras desenhadas e pintadas para neo do nanelógrafo servem para o mesmo flm. De muita utilidade sāo as cairas de fósfo ros vazlas para a fabricaçāo de mesas, camas, cadeiras, etc., que podem ser pintadas em côres, numa uniäo de pintura e ar teranato.

Com rolhss poderāo as crianças fazer qual quer tipo de animal, utilizando pálitos de fósforo na confecção das pernas e papel recortado no formato de orelhas.

Para desenvolver força e habilidade poderão usar bolas para futebol feitas de qualquer material, petécas con feccionadas por êles próprios, assim como espadas de madeira para esgrima e muitos outros brinquedos.

Para o escolar há necessidade de brinquedos que estimulem o aprendizado e quando êles tomam parte na con fecção o àproveitamento é bem maior. Os quebra-cabeças de mapas ou qualquer acidente geográfico; as letras feltas de pa pelāo; 08 jogos com cartöes de viagens indicando as cidades por onde passam; os objetos de madeira ou de outro material qual quer indicando a conduçāo, muito contribuem para o aprendiza do de meios de transporte e das cldades dos diferentes estados e países. Ao darmos ao menino material de carpintaria e à me nina material de costura, estamos oferecendo maior oportuni dade para porem em açāo seu espírito criador e sua imaginaçāo brilhante na execuçāo daquilo que lhe trará satisfação interior, contribuindo ao mesmo tempo, para o desenyolvimento de uma personalidade dinâmica.

Mencionamos aqui alguns materiais de brin quedo que pouco ou nada custaräo aos pais mas que muito conn tribuirāo para o desenvolvimento neuro-psico-motor da crian ça nas várlas etapas de sua vida.

Como è natural aqui apresentamos apenas uma Idéla do que pode ser felto; procuramos somente demong trar que a recreação da criança pode e deve ser feita sem gas tos ou despendendo pouco e que a alegagāo de que a situação é conómica nāo permite dar à criança brinquedos, nāo procede. 
Pensando ter dado aos pais, numa linguagem simples e accessível a todos, alguma contribuiçāo para que tor ne seus filhos mais felizes, podemos acrescentar ainda que a música nunca deverá ser esquecida, pois é a definição de uma arte para a qual muitos teräo pendor.

\section{Referências Bibliográficas}

1. BRASIL, Ministério da Educaçāo e Saúde - Brinquedos e jo gos conforme a idade. Serviço de Propaganda e Edu cação Sanitária. Rio de Janeiro, 1939.

2. ESTADOS UNIDOS - Secretaria de Estado - Comitê, Interde partamental de cooperação cientifica cultural - Jogos e brinquedos caseiros para criança de idade pré-esco lar. Washington, s.c.p., s.d.

3. LUCIANA, D. - Como fazer brinquedos originais. (Ediçöes de Ourol. Rio de Janeiro, Tecnoprint, 1963.

4. MIRANDA, N. - Jogos motores para crianças de 4 a 6 anos. Departamento de Cultura. São Paulo, 1943.

5. MIRANDA, N. - Jogos motores para crianças de 7 a 9 anos e 10 a 12 anos. Departamento de Cultura. Sāo Paulo,1943.

6. MONTEIRO, P.J. - Puericultura. Barcelona, Jims, 1966.

7. $O$ MUNDO DA CRIANÇA - Aprendendo a brincar. Rio de Janeiro, Delta, 1954.

8. MYRA y LOPES, E. - Psicologia evolutiva da criança e do adolescente. 3a.ed. Cientifica. Rio de Janeiro,1946.

9.PAGE, H. - O brinquedo e as crianças. São Paulo, Anhanguera, 6. d. 
98

10.SCHMIDT, Maria J. - Educar para recreaçño. 2a.ed. Rio de Janeiro, Agir, 1960.

11.SIL VA,Y.R.da - Nós e a criança. Pôrto Alégre, Globo, 1963.

VELLOSO.N.cie A. - Importância do brinquedo no desenvolvimento da criança. Revista da Escola de Enfermagem da USP, $1(1): 89-$ 98, out. 1967. 